\title{
A Primeira Década do Prouni: Estudo Sobre a EFICIÊNCIa a Partir da ANálise Econômica do Direito
}

\author{
Gilberto Alexandre de Abreu Kalil* \\ Oksandro Osdival Gonçalves* *
}

\begin{abstract}
1 Introdução. $2 \mathrm{O}$ desenvolvimento pelo acesso à educação. $3 \mathrm{O}$ direito à educação e a reserva do possível. 4 Prouni: uma abordagem da política pública a partir da análise econômica do direito. 5 Os postulados de aplicação da AED: a escolha racional e a eficiência. 6 A maximização do resultado. 7 Conclusão. Referências.
\end{abstract}

\section{RESUMO}

Para tornar mais efetivo o direito à educação, o Estado pode criar políticas públicas, como o Programa Universidade para Todos (Prouni), instituído pelo Governo Federal no ano de 2005, que concede bolsas de estudo integrais e parciais a estudantes de baixa renda em instituições de Ensino Superior privadas, que em contrapartida ficam isentas do pagamento de tributos federais. Nesse cenário, o principal objetivo do presente artigo é avaliar a referida política pública por uma perspectiva interdisciplinar, utilizando-se a Análise Econômica do Direito (AED). Assim, o artigo analisa se a primeira década de existência do Prouni, compreendida entre os anos de 2005 a 2015, produziu resultados eficientes para a finalidade que ensejou a concepção da política pública, qual seja, concretizar o direito fundamental social à educação pela ampliação do acesso ao Ensino Superior aos estudantes menos favorecidos economicamente.

Palavras-chave: Políticas públicas. Educação. Programa Universidade para Todos. Análise Econômica do Direito.

\section{INTRODUÇÃO}

No Brasil, como reflexo da injusta distribuição de renda, o Ensino Superior costumava ser privilégio das classes mais favorecidas economicamente, ${ }^{1} \mathrm{o}$ que aprofundava mais o processo de desigualdade econômica e social. ${ }^{2}$ Para combater essa circunstância, no ano de 2005, o Governo Federal instituiu o Programa Universidade para Todos (Prouni), que concede

* Mestre em Direito Econômico pela Pontifícia Universidade Católica do Paraná. Professor de Direito Tributário da Faculdade Cidade Verde. Membro do grupo de estudos em Análise Econômica do Direito do Programa de Pós-Graduação em Direito da Pontifícia Universidade Católica do Paraná. E-mail: < gilberto@ kecadvocacia.com.br $>$.

** Doutor em Direito Comercial pela Pontifícia Universidade Católica de São Paulo. Mestre em Direito Econômico pela Pontifícia Universidade Católica do Paraná. Professor do Programa de Pós-Graduação em Direito (Mestrado/Doutorado) da Pontifícia Universidade Católica do Paraná. E-mail: <oksandro@cgaadv.com.br>. 
bolsas de estudo integrais e parciais para estudantes carentes em instituições privadas de Ensino Superior, que, em contrapartida, são beneficiadas com a isenção de tributos federais.

Nesse cenário, o principal objetivo do presente artigo é avaliar, pela perspectiva da Análise Econômica do Direito (AED), método de abordagem do Direito cuja principal característica reside na integração entre a ciência jurídica e a ciência econômica (RIBEIRO; CAMPOS, 2013, p. 313), se a primeira década de existência do Programa Universidade para Todos (Prouni) produziu resultados eficientes para a finalidade que ensejou a concepção da política pública, qual seja, ampliar o acesso ao Ensino Superior dos estudantes carentes.

Primeiramente, o estudo começará pela análise da importância do acesso à educação para o desenvolvimento do país. Depois, será investigada a obrigação do Estado de concretizar o direito à educação levando em consideração que são limitados os recursos estatais. Na sequência, o foco será delinear brevemente a sistemática de funcionamento do Prouni, abordando o programa a partir da Análise Econômica do Direito (AED) e dos postulados necessários ao entendimento desse método de compressão das normas jurídicas. Ao final, serão analisados dados do Prouni, no período compreendido entre os anos de 2005 a 2015, principalmente com relação ao ingresso de estudantes no Ensino Superior pela política pública, à renúncia fiscal em razão da isenção de tributos federais concedidas às instituições privadas de Ensino Superior, ao custo para o Estado por bolsa concedida, dentre outros.

\section{O DESENVOLVIMENTO PELO ACESSO À EDUCAÇÃO}

A Constituição Federal de 1988 (BRASIL, 1988), quando elevou a garantia do desenvolvimento nacional à categoria de objetivo fundamental da República, impôs uma série de obrigações ao Estado que não se limitam à busca pelo incremento do Produto Interno Bruto (PIB). Foi muito além disso para endereçar outros deveres ao Estado. $\mathrm{O}$ desenvolvimento, na perspectiva constitucional, exige um conjunto de fatores, dentre eles o avanço na implementação de direitos sociais, como a educação.

O desenvolvimento é um processo de longo prazo, induzido por políticas públicas ou programas de ação governamental em três setores interligados: econômico, social e político. $\mathrm{O}$ elemento econômico se realiza com o aumento na produção de bens e serviços. $\mathrm{O}$ elemento social manifesta-se pelo avanço na igualdade de condições básicas à existência dos indivíduos, o que depende da implementação de direitos de caráter econômico, social e cultural, como o direito à educação. $\mathrm{O}$ elemento político implica a participação do povo na democracia, assumindo seu papel de sujeito político, enquanto fonte legitimadora do poder e destinatário do seu exercício (COMPARATO, 2010, p. 411-412).

Mesmo figurando entre as maiores economias do mundo, ${ }^{3}$ o Brasil ainda é marcado pela distribuição irregular da renda e, ${ }^{4}$ além disso, por um baixo grau de efetividade dos direitos fundamentais sociais, o que impede que todos tenham acesso a direitos tão essenciais quanto à educação, fator que constituiu óbice ao desenvolvimento na perspectiva constitucional. 
Conforme pesquisa da Organização para a Cooperação e Desenvolvimento Econômico (OCDE), no Brasil, as taxas de emprego são $70 \%$ maiores para aqueles que alcançam o Ensino Superior em comparação com aqueles que somente concluíram o Ensino Médio. De acordo com o mesmo estudo, o ensino universitário também produz impacto significativo na renda, pois os indivíduos que possuem essa formação ganham, em média, 150\% a mais do que aqueles apenas com Ensino Médio (ORGANIZAÇÃO PARA COOPERAÇÃO E DESENVOLVIMENTO ECONÔMICO, 2013).

Portanto, o ensino universitário é indispensável para que os indivíduos consigam a capacitação educacional necessária para os melhores empregos, o que colabora na redução das desigualdades sociais e econômicas e, consequentemente, para o desenvolvimento. De outro lado, a educação também realiza o elemento econômico do desenvolvimento. Para industrializar produtos de maior valor agregado, é fundamental que o Estado incentive a pesquisa científica e a inovação tecnológica nas instituições de Ensino Superior.

A educação permite, ainda, aos indivíduos um maior conhecimento dos aspectos que envolvem o exercício da cidadania em um Estado Democrático de Direito, dentre eles, a importância do processo eleitoral para a escolha de seus representantes. A concretização progressiva dos direitos fundamentais sociais, o que inclui a criação de políticas públicas educacionais, é indispensável para a consagração do conceito pós-moderno de democracia, o qual, "superando a ideia de mera representatividade formal, pressupõe uma participação consciente e com capacidade real de influência nas decisões políticas da comunidade." (REIS, 2015, p. 9). Por isso, somente haverá desenvolvimento, na concepção escolhida pela Constituição Federal, quando o incremento econômico estiver acompanhado de progresso social e político, que seja capaz de produzir como consequência a redução das desigualdades sociais e econômicas, para o que é necessário o acesso a bens, como a educação.

\section{O DIREITO À EDUCAÇÃO E A RESERVA DO POSSÍVEL}

O art. 205 da Constituição Federal trata a educação como direito de todos e dever do Estado e da família, devendo ser promovida e incentivada com a colaboração de toda a sociedade, com vistas a atingir o pleno desenvolvimento da pessoa, além do seu preparo para o exercício da cidadania e a sua qualificação para o trabalho. Embora toda sociedade seja corresponsável pela implementação do direito à educação, o Estado precisa contar com recursos financeiros para garantir o acesso dos indivíduos a esse direito, o que exige a discussão da chamada reserva do possível.

A reserva do possível surgiu na década de 70, quando a Corte Constitucional da Alemanha discutia em um processo a constitucionalidade das restrições ao direito de livre escolha da profissão, pois o número de vagas nas universidades públicas de medicina era inferior à demanda estudantil. Naquela ocasião, a decisão declarou que as pretensões individuais 
estavam submetidas à reserva do possível, no sentido de que esses pleitos formulados contra o Estado fossem analisados com a devida razoabilidade (FONTE, 2014, p. 141).

A reserva do possível condiciona a efetividade dos direitos fundamentais sociais à capacidade financeira do Estado, que, apesar de dispor dos recursos financeiros, não está obrigado a prestar algo que extrapole os limites do razoável (SARLET; FIGUEIREDO, 2007). Quando se trata da educação, essa razoabilidade pode ser extraída da proteção jurídica mais privilegiada que foi outorgada a certas parcelas desse direito. É o que ocorre com a Educação Básica, que compreende a Educação Infantil, o Ensino Fundamental e o Ensino Médio, nos termos do art. 21, inc. I, da Lei nº 9.394/1996, Lei de Diretrizes e Bases da Educação (BRASIL, 1996).

A Constituição Federal (art. 208, inc. I) determinou que o dever do Estado com a educação será efetivado mediante a garantia de Educação Básica obrigatória e gratuita dos 4 aos 17 anos de idade. Nessa linha, o Supremo Tribunal Federal entende que a cláusula da reserva do possível não pode ser invocada pelo Poder Público para inviabilizar a implementação de políticas públicas estabelecidas pela própria Constituição, como ocorre no caso da Educação Básica. Isso porque se trata de uma parcela do direito que visa a garantir o mínimo existencial, ${ }^{5}$ que decorre da dignidade da pessoa humana. Portanto, não há escusa que legitime a omissão estatal com relação à Educação Infantil, o Ensino Fundamental e o Ensino Médio. 6

O Ensino Superior, art. 208, inc. V, da Constituição Federal (BRASIL, 1988), por sua vez, trata-se de desdobramento do direito à educação que extrapola a proteção constitucional conferida ao direito à Educação Básica. Aumentar progressivamente o acesso ao Ensino Superior em instituições públicas de ensino exige um grande volume de recursos estatais. De acordo com dados do Instituto Nacional de Estudos e Pesquisas Educacionais Anísio Teixeira (INEP), no ano de 2013, o investimento público direto em educação por estudante do Ensino Superior foi de $\mathrm{R} \$ 23.383,00 .^{7}$ Isso demonstra que a reserva do possível é uma circunstância real que afeta o grau de efetividade do direito à educação no caso do Ensino Superior.

No entanto, o fato de um direito estar condicionado à existência de recursos financeiros não destrói a qualidade jusfundamental da garantia em causa (NOVAIS, 2010, p. 279). O reconhecimento de um conteúdo mínimo para a existência digna não faz que os direitos fundamentais sociais, naquelas parcelas que extrapolam o mínimo necessário à proteção da dignidade, deixem de ser fundamentais (BITTENCOURT NETO, 2010, p. 118). Logo, o Ensino Superior não é mais nem menos fundamental apenas porque o seu conteúdo supera o mínimo para viver dignamente. Entender que um direito fundamental social não pode ser tutelado em determinado caso concreto pela via judicial não atenua a obrigação da Administração Pública de atuar com vistas à sua efetivação. Reconhecer judicialmente que a demanda estudantil pelo Curso de Medicina é superior à capacidade orçamentária do Estado de criar vagas, como fez a Corte Constitucional da Alemanha, ou ainda que determinada 
parcela do direito à educação escapa dos limites orçamentários previstos pelo Poder Legislativo, não autoriza o Estado a deixar de lado o objetivo de atuar no sentido universalizar o acesso àquelas posições jurídicas que extrapolam as parcelas da Educação Básica.

Por exigência de um constitucionalismo igualitário, torna-se imprescindível o dever do Estado de buscar garantir a integralidade do conteúdo dos direitos fundamentais sociais (HACHEM, 2014, p. 87). Embora o mínimo existencial (Educação Básica) aponte uma obrigação mínima do Estado, na realidade, os direitos sociais reclamam um horizonte eficacial progressivamente mais vasto, que indica para uma ideia de máximo possível (CLÈVE, 2012, p. 28). O dever de atuação maximizada do Estado decorre de dois fundamentos: (i) a igualdade material e (ii) o direito ao desenvolvimento. A concretização da igualdade material exige que, além de oferecer as condições iniciais de vida, o Estado atue no sentido de reaproximar as posições distribuídas na sociedade, mediante a redução das disparidades de renda e condições de vida, para o que é necessária a melhor distribuição dos recursos. No que diz respeito ao desenvolvimento, os objetivos fundamentais da República (art. $3^{\circ}$ da CF) configuram uma decisão política do constituinte cuja finalidade é compelir o Estado a otimizar a qualidade de vida da população. Para isso, não basta eliminar as condições miseráveis dos brasileiros, mas, também, a desigualdade social existente entre os indivíduos (HACHEM, 2013, p. 370-385).

A Constituição Federal, quando enunciou que a educação é um direito de todos (art. 205), não fez outra coisa senão recorrer ao princípio da igualdade. Mesmo que seja utópico cogitar que as prestações materiais devidas pelo Estado com relação ao direito à educação possam ser distribuídas igualmente entre todos os cidadãos, já que a reserva possível "não é algo artificialmente construído pela doutrina, mas um condicionamento real" (NOVAIS, 2010, p. 278), tal circunstância não pode ser óbice para que o Estado busque a maximização das posições jurídicas que decorrem do direito à educação, como o acesso ao Ensino Superior.

Não se atinge o desenvolvimento, na concepção escolhida pela Constituição, somente garantindo o acesso à Educação Básica. Entretanto, não se pode ignorar que há um limite orçamentário decorrente da natural escassez de recursos financeiros para o atendimento de todos. Por isso, é preciso que o Estado administre de forma racional os recursos públicos adotando medidas que resultem na máxima efetivação das parcelas do direito à educação ao menor custo possível e de modo a atingir a maior quantidade possível dos seus titulares.

\section{PROUNI: UMA ABORDAGEM DA POLÍTICA PÚBLICA A PARTIR DA ANÁLISE ECONÔMICA DO DIREITO}

O Prouni foi instituído pela Medida Provisória no. 213/2004, posteriormente, convertida na Lei $n^{\circ} .11 .096 / 2005$. Nos termos do art. $1^{\circ}$ da referida Lei, o programa objetiva conceder bolsas de estudo integrais e parciais para estudantes de baixa renda em cursos de 
graduação e sequenciais de formação específica, em instituições privadas de Ensino Superior, com ou sem fins lucrativos. Para concorrer às bolsas integrais, os estudantes devem possuir renda familiar bruta mensal de até um salário mínimo e meio por pessoa $\left(\operatorname{art} .1^{\circ}, \S 1^{\circ}\right.$, Lei $\mathrm{n}^{\mathrm{O}}$. 11.096/2005), enquanto as bolsas parciais de 50\% são destinadas para os estudantes cuja renda brutal mensal seja de até três salários mínimos por pessoa $\left(\operatorname{art} .1^{\circ}, \S 2^{\circ}\right.$, Lei n ${ }^{\circ}$. 11.096/2005) (BRASIL, 2005b).

Para concretizar a adesão das instituições de Ensino Superior ao Prouni, a Lei $n^{\mathrm{o}}$. 11.096/2005 oferece, em contrapartida, a isenção de tributos federais, nos termos do art. $8^{\circ}$. De acordo com caput do art. $8^{\circ}$ e seu $\S 1^{\circ}$, a isenção recairá sobre o lucro nas hipóteses do Imposto de Renda das Pessoas Jurídicas (IRPJ) e Contribuição Social sobre o Lucro Líquido (CSLL), e sobre a receita auferida, nas hipóteses de Contribuição Social para Financiamento da Seguridade Social (COFINS) e Contribuição para o Programa de Integração Social (PIS), decorrentes da realização de atividades de Ensino Superior, proveniente de cursos de graduação ou cursos sequenciais de formação específica.

Percebe-se, portanto, que o Prouni é uma política pública extrafiscal. A extrafiscalidade é formada por um conjunto de normas que, embora façam parte do Direito Fiscal, não possuem como finalidade dominante a consecução de receitas para o Estado, mas objetivam realizar determinada finalidade econômica ou social (NABAIS, 1998, p. 629). A extrafiscalidade pode exteriorizar-se sob diversas formas. ${ }^{8}$ No caso do Prouni, a extrafiscalidade manifesta-se por meio da técnica da isenção.

Nos termos dos arts. 175 e 176 do Código Tributário Nacional, a isenção é modalidade de exclusão do crédito tributário que decorre de lei que especifique as condições e os requisitos exigidos para a sua concessão ao tributo a que se aplica e o seu prazo de duração. Leandro Paulsen, ao investigar a natureza jurídica da isenção, explica que "surge a obrigação, mas o respectivo crédito não será exigível; logo, o cumprimento da obrigação resta dispensado.”(PAUSEN, 2007, p. 1129). Quando isenta, o Estado põe fim à imposição tributária e termina por induzir aquele comportamento desejável que ensejou a lei que concedeu a isenção. Quando isso ocorre, a isenção converte-se em instrumento de política social e econômica, podendo ser manejada por razões sociais para assegurar o bem-estar geral (BORGES, 2011, p. 70-72), sendo útil, inclusive, para que o Estado forneça mais do que o mínimo existencial do direito à educação, como ocorre com o Prouni. De acordo com dados oficiais, na sua primeira década de existência, foram concedidas mais de 2,5 milhões de bolsas parciais e integrais, como se pode observar no gráfico abaixo: 


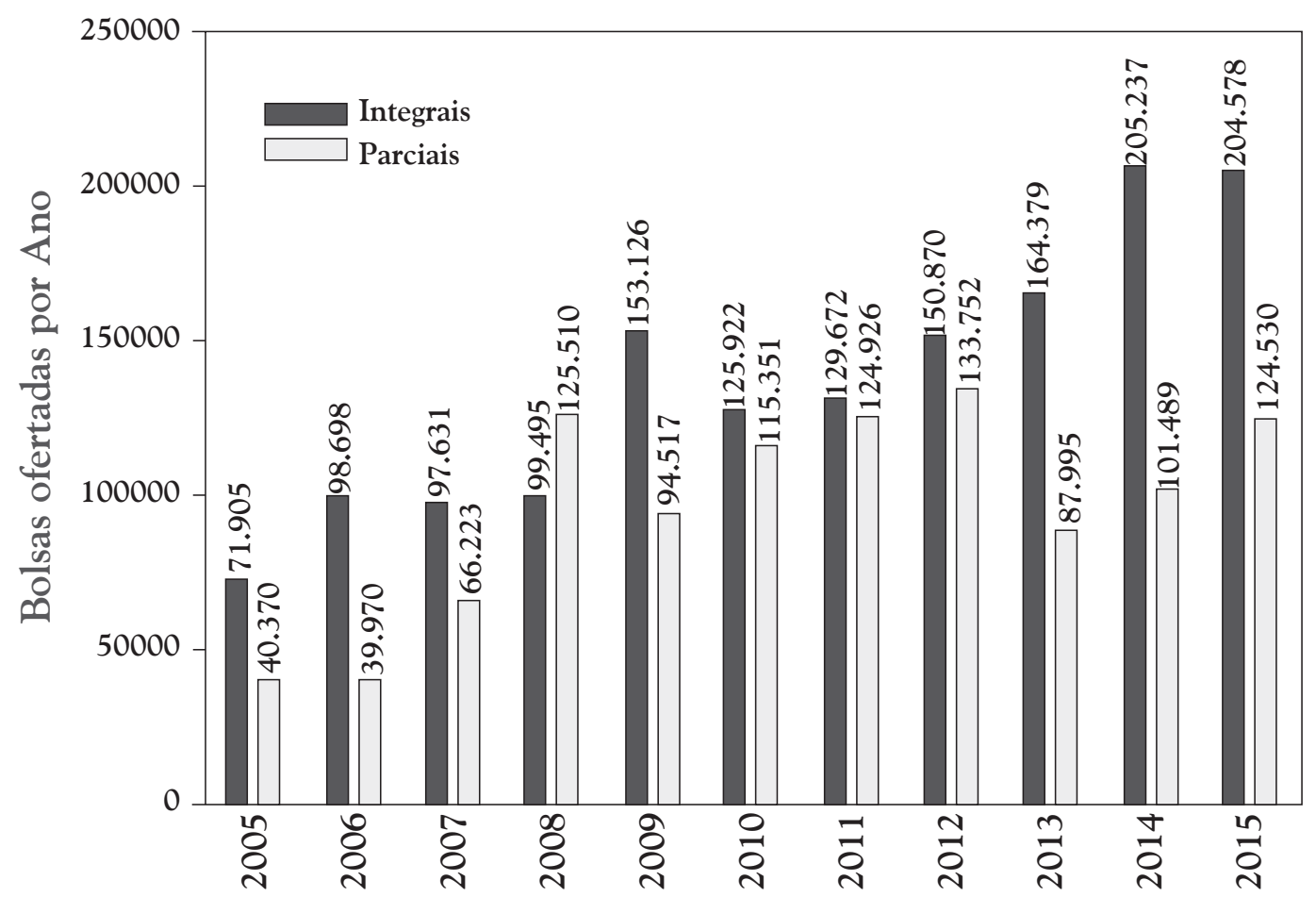

Gráfico 1 - Bolsas concedidas

Fonte: (BRASIL, 2015b).

Embora os dados apontem um expressivo aumento do acesso ao Ensino Superior, é preciso investigar se essa forma de implementação do direito à educação produz os resultados mais eficientes frente ao objetivo estatal de conferir a máxima efetividade ao direito, considerando-se, ainda, a limitação dos recursos estatais. Para isso, pode-se recorrer à Análise Econômica do Direito (AED), como instrumento de abordagem da política pública. A AED consiste na aplicação do instrumental analítico e empírico da economia, sobretudo da microeconomia e da economia do bem-estar social, na tentativa de compreender, explicar e prever as consequências fáticas das normas jurídicas (SALAMA, 2008, p. 9). A AED possui como principais características: (i) a rejeição da autonomia do Direito frente à realidade social e econômica; (ii) a utilização de métodos de outras áreas do conhecimento, como a economia; (iii) a crítica à interpretação jurídica baseada somente no direito, sem referência ao contexto econômico e social (CALIENDO, 2009, p. 205).

A AED vai além da análise isolada e puramente dogmática das normas jurídicas para levar em consideração também os efeitos reais do ordenamento jurídico. Para fazê-lo, a AED vale-se de dois níveis epistemológicos, uma vertente chamada positiva e outra normativa. A dimensão positiva (ou descritiva) ocupa-se das repercussões do Direito sobre o mundo real dos fatos. A dimensão normativa (ou prescritiva) tem por objetivo investigar como as noções de justiça se comunicam com os conceitos de eficiência econômica, maximização da riqueza e maximização do bem-estar social (SALAMA, 2008, p. 9). 
Gico Junior (2010, p. 20-21) explica que, a partir dessas duas vertentes, os juseconomistas visam a dar respostas a duas indagações: "(i) quais as consequências de um dado arcabouço jurídico, isto é, de uma dada regra; e (ii) que regra jurídica deveria ser adotada." Quando se utiliza a AED para fazer uma análise positiva, realiza-se um exercício de prognose, isto é, uma verificação da eficiência de determinada norma jurídica. No caso do Prouni, como a política pública já foi instituída desde o ano de 2005, é possível valer-se da dimensão positiva para a investigação de alguns de seus efeitos. Essa abordagem permite investigar a eficiência da tributação extrafiscal, isto é, a dimensão positiva pode funcionar para avaliar se os efeitos de determinado incentivo fiscal conduzem à maximização do bem-estar a um menor custo para o Estado.

\section{OS POSTULADOS DE APLICAÇÃODA AED: A ESCOLHA RACIONALE A EFICIÊNCIA}

Feita a diferenciação dos níveis epistemológicos da AED, é preciso compreender os seus postulados. Os princípios em torno dos quais gravita a ciência econômica são: (i) a escolha racional ou maximização; (ii) o equilíbrio; e (iii) a eficiência. Esses fatores, essenciais ao entendimento da AED, revelam que os indivíduos tomam decisões e fazem suas escolhas, de forma racional, visando à melhoria de sua própria condição individual, isto é, a maximização de seu bem-estar (RIBEIRO; GALESKI JUNIOR, 2009, p. 77).

Partindo-se do pressuposto de que os agentes privados são racionais e visam a maximizar o resultado de suas atividades, o tributo extrafiscal pode incentivar a adoção de determinada conduta com vistas à realização de um objetivo perseguido pelo Estado. Isso ocorre porque as normas tributárias impactam fortemente os custos de transação, pois aumentam a complexidade do ambiente de negócios e, consequentemente, alteram a perspectiva da tomada de decisões (GONÇALVES; RIBEIRO, 2013, p. 85-86). Se a extrafiscalidade for utilizada para mitigar ou, até mesmo, excluir a incidência de um tributo, terminará por reduzir os custos de transação e, como consequência, poderá induzir o contribuinte a praticar uma determinada conduta. No caso do Prouni, a isenção de tributos federais desonera as instituições privadas de Ensino Superior e, ao fazê-lo, diminui parte dos seus custos operacionais, o que estimula a concessão de bolsas, porque esse é um comportamento economicamente viável. Trata-se de uma escolha racional que além de conduzir à maximização do resultado econômico da instituição de Ensino Superior que concede a bolsa de estudo, resulta em maior implementação do direito à educação, pois amplia o acesso da população mais carente ao Ensino Superior.

Por sua vez, a eficiência costuma ser associada ao bem-estar, à diminuição de custos e à maximização da riqueza (SALAMA, 2008, p. 22). Em termos jurídicos, "uma lei será mais eficiente que outra se for capaz de atingir os mesmos resultados através de custos menores." (GONÇALVES; RIBEIRO, 2013, p. 83). Por isso, as políticas públicas, mesmo aquelas baseadas na extrafiscalidade dos tributos, devem visar a atingir os melhores resultados e, simultaneamente, onerar o mínimo possível o Estado. Para Paulo Caliendo (CALIENDO, 
2009, p. 217-219), a eficiência é a maximização de determinados bens sociais entendidos como de grande importância (a educação é um desses bens). Na economia do bem-estar, existem dois importantes aspectos: a eficiência econômica (economic efficiency) e a distribuição de renda (income distribution). A primeira visa a fazer crescer o bolo econômico, ao passo que a segunda se ocupa de como repartir o bolo econômico. A eficiência distributiva é a capacidade de distribuir melhor os bens para aqueles que realmente necessitam.

O cenário que antecedia a instituição do Prouni, marcado por um baixo acesso da população ao Ensino Superior, sobretudo dos mais carentes, denunciava a necessidade de uma política pública com escopo redistributivo, que tivesse como base a renda como um dos principais critérios de inclusão. No entanto, não basta apenas instituir políticas públicas com essa intenção, é preciso que elas sejam eficientes, já que os recursos são escassos para atender a todos. A alocação dos recursos públicos para concretizar determinado objetivo estatal deve ser feita da maneira mais eficiente possível (isto, é maximizando seus efeitos), sob pena de ser injusta e desviada da finalidade para a qual foi concebida a política pública.

Essa premissa, que se forma com base na eficiência a partir da $\mathrm{AED}$, não é um raciocínio puramente econômico. A eficiência decorre da própria Constituição Federal. O princípio constitucional da eficiência administrativa (art. 37 da CF) impõe à Administração Pública o dever de: (i) exercitar sua competência com a máxima celeridade, presteza, economicidade e produtividade; (ii) atuar para realizar a finalidade pública subjacente às normas jurídicas às quais está submetida; (iii) utilizar os meios mais adequados ao alcance ótimo dos objetivos previstos pelas normas; (iv) conferir a máxima efetividade aos comandos que lhes são dirigidos pelo ordenamento público; (v) guardar consonância com os direitos fundamentais e com os princípios que orientam a atividade administrativa (GONÇALVES; HACHEM, 2010, p. 245). No caso do Prouni, a ampliação das vagas ocorre na rede privada, mas a iniciativa partiu do Estado quando instituiu a política pública extrafiscal. Quando age dessa forma, parece adequado entender que a ação estatal sofre influência desses desdobramentos que decorrem do conteúdo jurídico do princípio da eficiência, previsto no art. 37 da Constituição Federal.

Na AED, a eficiência costuma ser analisada sob dois enfoques: os critérios de eficiência de Pareto e de Kaldor-Hicks. Será Pareto-eficiente uma situação que produza benefícios para um indivíduo sem que haja prejuízos à condição de outro agente. Esse critério tem pouca aplicação prática, pois a maioria das transações tem repercussões sobre terceiros. $\mathrm{O}$ critério de eficiência de Kaldor-Hicks, por sua vez, parte do pressuposto de que as normas devem ser planejadas visando a causar o máximo de bem-estar para o maior número de pessoas, isto é, os ganhos totais devem compensar as eventuais perdas sofridas por alguém (RIBEIRO; GALESKI JUNIOR, 2009, p.86-87).

O critério de Kaldor-Hicks permite que mudanças sejam implementadas ainda que haja perdedores (SALAMA, 2008, p. 24). Para atender a esse critério, as normas tributárias extrafiscais concebidas para realizar objetivos não arrecadatórios, como faz o Prouni, devem produzir a maior quantidade de bem-estar possível para o maior número de pessoas, sem que 
isso importe custos adicionais superiores aos benefícios para outros agentes econômicos. Com base nessas premissas teóricas, é que se passa à análise sobre alguns aspectos econômicos do Prouni, sobretudo para verificar a eficiência da política pública.

\section{A MAXIMIZAÇÃO DO RESULTADO}

O Prouni ampliou o acesso ao Ensino Superior dos estudantes de baixa renda, contudo a isenção dos tributos federais provocou prejuízos na arrecadação da União Federal, fato que tem sido alvo de críticas. Embora os argumentos sejam variados, muitos deles convergem no sentido de entender o Prouni como uma estratégia de transferência de recursos públicos para as instituições privadas feita no interesse dos empresários do setor, promovendo, ainda que por via reflexa, a privatização do ensino em detrimento da expansão das vagas na rede pública de Ensino Superior. ${ }^{9}$ De acordo com dados oficiais, estima-se que a cifra não arrecadada pela União nos anos de 2005 a 2015 já ultrapassou o montante de 5 bilhões de reais, como se pode observar na Tabela 1. ${ }^{10}$

\section{Tabela 1 - Renúncia fiscal}

\begin{tabular}{|c|c|c|c|c|}
\hline Ano & $\begin{array}{c}\text { Valor da } \\
\text { Renúncia Fiscal }\end{array}$ & $\begin{array}{l}\text { Total de Bolsas } \\
\text { Concedidas }^{1}\end{array}$ & Valor/Bolsa ${ }^{2}$ & $\begin{array}{c}\text { Investimento } \\
\text { Público }\end{array}$ \\
\hline 2005 & $106.737 .984,00$ & $112.275,00$ & 950,68 & $16.361,00$ \\
\hline 2006 & $265.740 .831,00$ & $138.668,00$ & $1.916,38$ & $16.938,00$ \\
\hline 2007 & $126.050 .707,00$ & $163.854,00$ & 769,29 & $17.897,00$ \\
\hline 2008 & $434.173 .655,00$ & $225.005,00$ & $1.929,62$ & $16.542,00$ \\
\hline 2009 & $502.673 .842,00$ & $247.643,00$ & $2.029,83$ & $18.579,00$ \\
\hline 2010 & $625.367 .277,00$ & $241.273,00$ & $2.591,95$ & $19.748,00$ \\
\hline 2011 & $510.901 .338,00$ & $254.598,00$ & $2.006,70$ & $21.041,00$ \\
\hline 2012 & $733.904 .013,00$ & $284.662,00$ & $2.578,16$ & $19.110,00$ \\
\hline 2013 & $750.943 .828,00$ & $252.374,00$ & $2.975,52$ & $21.383,00$ \\
\hline 2014 & $601.118 .818,00$ & $306.726,00$ & $1.959,79$ & $*$ \\
\hline 2015 & $970.434 .955,00$ & $329.117,00$ & $2.948,60$ & $*$ \\
\hline Valor Total & $5.626 .790 .259,00$ & $2.556 .195,00$ & $22.647,46$ & $167.599,00$ \\
\hline \multicolumn{5}{|c|}{$\begin{array}{l}\text { Todos os valores estão expressos em Reais }(R \$) \text {. } \\
{ }^{1} \text { Bolsas integrais e parciais concedidas por ano. } \\
{ }^{2} \mathrm{O} \text { valor foi obtido pela divisão da renúncia fiscal por ano pelo número de bolsas integrais e parciais concedidas por ano. } \\
{ }^{3} \text { investmento público direto em educação superior por edtudante. } \\
{ }^{*} \text { Dados não encontrados. }\end{array}$} \\
\hline
\end{tabular}

Fonte: (BRASIL, 2015b).

A divisão dos valores anuais da renúncia fiscal pela quantidade total de bolsas parciais e integrais concedidas por ano aponta o custo anual médio para a concessão de cada benefício. Esses dados, quando comparados com o investimento público direto anual feito pelo Estado por estudante do Ensino Superior, ${ }^{11}$ revelam um aspecto interessante a respeito do impacto econômico do programa. 
Apesar da cifra não arrecadada na primeira década de existência do Prouni ser bastante significativa, o custo da isenção para o Estado é inferior ao investimento anual por aluno no Ensino Superior público. Portanto, ao menos com relação às atividades de Ensino Superior, o Prouni atende ao critério de eficiência de Kaldor-Hicks, pois "produz a maior quantidade de resultados com a menor utilização dos meios" (CALIENDO, 2008, p. 70), colaborando, ainda, para uma melhor distribuição da educação enquanto bem essencial para todos, sobretudo para a parcela mais carente da população.

Muitas vezes, o estudante da rede pública de Ensino Básico não consegue concorrer em igualdade de condições com os estudantes egressos da rede privada às vagas nas universidades públicas. Prova disso é o resultado do Exame Nacional do Ensino Médio (ENEM). No ano de 2014, somente 93 escolas públicas entraram no ranking das mil escolas com as melhores notas no exame, o que equivale a menos de $10 \%$ do total. ${ }^{12}$ Esse dado é um forte indicativo da baixa qualidade do Ensino Básico na rede pública. Por isso, os mais abastados, que têm uma Educação Básica de melhor qualidade (na rede privada), possuem mais chances de ingressar no Ensino Superior público e, quando isso não ocorre, podem pagar pelo acesso a esse bem. Todavia, a parcela da população mais desfavorecida economicamente e, como uma das consequências disso, sem acesso a uma Educação Básica de boa qualidade (na rede pública), enfrenta mais dificuldades de acessar o Ensino Superior público e, quando isso ocorre, na maioria das vezes, não pode pagar pelo acesso a esse bem.

No entanto, o baixo custo por vaga do Prouni também é alvo de críticas. Para Davies (2004, p. 247), apesar do custo menor, a pesquisa científica e o atendimento médico em hospitais universitários concentram-se nas universidades públicas, pois são atividades que pelo seu alto custo não atraem as instituições privadas, que ficam concentradas apenas nas atividades de ensino. Na perspectiva de Carvalho (2011, p. 14), a isenção "reduz o volume de recursos vinculados ao segmento federal, na medida em que o art. 212 da CF de 1988 determina que $18 \%$ da receita de impostos deve ser destinada à educação pública.”

Não se pode ignorar o fato de que, ao estimular a iniciativa privada pela isenção fiscal, o Estado deixa de incorrer em custos inevitáveis na rede pública, como o pagamento de salários dos professores e demais servidores públicos, gastos com a manutenção e expansão da infraestrutura das universidades públicas, o direcionamento de verbas para pesquisa científica, dentre outros. No entanto, as críticas acima devem ser analisadas à luz do texto constitucional. Se, por um lado, no modelo brasileiro, a pesquisa científica de ponta encontra-se principalmente nas universidades públicas, por outro, a Constituição Federal tratou a educação como um direito de todos (art. 205). Sendo esta a escolha do legislador constitucional, parece adequado entender que o seu objetivo foi endereçar ao Estado o dever de atuar no sentido de universalizar o acesso a todos os níveis de ensino, inclusive ao Ensino Superior, o que pode ser feito em colaboração com a iniciativa privada, mediante estímulo fiscal do Estado.

A expansão da rede privada de ensino, como consequência do Prouni, que custa menos ao Estado do que a expansão na rede pública, não parece estar em dissonância com a Constituição 
Federal (BRASIL, 1988), que consagrou um sistema de ensino que conjuga a ação pública com a privada (art. 209). E, ainda que isso acabe por favorecer uma lógica mercadológica que concentra as atividades dessas instituições no ensino e não em outras atividades acadêmicas mais custosas, possibilitar o acesso ao Ensino Superior é um passo inicial para que, posteriormente, o país avance mais em pesquisa científica. Para mitigar este efeito negativo, a Lei do Prouni poderia ser aprimorada para exigir das instituições de Ensino Superior credenciadas o direcionamento de recursos às atividades de pesquisa científica, o que poderia ser feito na proporção das bolsas concedidas, pois, quanto maior o número de bolsas, maior é o benefício econômico da instituição com a isenção. Como existem no país mais instituições privadas do que públicas, ${ }^{13}$ essa exigência das instituições vinculadas ao Prouni poderia colaborar para melhorar o cenário do desenvolvimento científico e tecnológico do país mais rapidamente.

Quanto à crítica lançada por Carvalho, no sentido de que o Prouni acarreta a redução de recursos que seriam destinados à educação pública, é preciso destacar que a redação do art. 212 da Constituição Federal refere-se exclusivamente à receita resultante da arrecadação dos "impostos". No Prouni, a extrafiscalidade incide principalmente nas contribuições (Contribuição Social sobre o Lucro Líquido, Contribuição Social para Financiamento da Seguridade Social e Contribuição para o Programa de Integração Social), atingindo somente o imposto de renda das pessoas jurídicas. Por isso, o volume não arrecadado é maior nas contribuições, como indica a Tabela $2 .{ }^{14}$

Tabela 2 - Renúncia fiscal

\begin{tabular}{|c|c|c|c|c|c|}
\hline Ano & $\begin{array}{c}\text { Valor da } \\
\text { Renúncia PIS }\end{array}$ & $\begin{array}{c}\text { Valor da Renúncia } \\
\text { COFINS }\end{array}$ & $\begin{array}{c}\text { Valor da } \\
\text { Renúncia CSSL }\end{array}$ & Total $^{1}$ & $\begin{array}{c}\text { Valor da } \\
\text { Renúncia IRPJ }\end{array}$ \\
\hline 2005 & $*$ & $*$ & $*$ & $*$ & $*$ \\
\hline 2006 & $144.506 .532,00$ & $54.549 .701,00$ & $19.834 .372,00$ & $218.809 .605,00$ & $46.850 .226,00$ \\
\hline 2007 & $23.475 .355,00$ & $59.730 .034,00$ & $12.356 .280,00$ & $95.561 .669,00$ & $30.489 .037,00$ \\
\hline 2008 & $35.043 .071,00$ & $161.737 .253,00$ & $60.541 .965,00$ & $257.322 .289,00$ & $176.851 .366,00$ \\
\hline 2009 & $47.840 .424,00$ & $219.787 .374,00$ & $86.021 .879,00$ & $353.649 .677,00$ & $149.024 .165,00$ \\
\hline 2010 & $56.649 .141,00$ & $260.342 .760,00$ & $118.869 .249,00$ & $435.861 .150,00$ & $189.506 .127,00$ \\
\hline 2011 & $38.049 .649,00$ & $174.438 .333,00$ & $78.615 .912,00$ & $291.103 .894,00$ & $219.797 .444,00$ \\
\hline 2012 & $59.452 .425,00$ & $274.395 .808,00$ & $126.427 .291,00$ & $460.275 .524,00$ & $273.628 .490,00$ \\
\hline 2013 & $57.993 .025,00$ & $267.660 .113,00$ & $109.233 .026,00$ & $434.886 .164,00$ & $316.057 .665,00$ \\
\hline 2014 & $58.624 .676,00$ & $270.575 .429,00$ & $62.594 .852,00$ & $391.794 .957,00$ & $209.323 .860,00$ \\
\hline 2015 & $80.159 .538,00$ & $369.967 .099,00$ & $125.112 .719,00$ & $575.239 .356,00$ & $395.195 .600,00$ \\
\hline Valor Total & $601.793 .836,00$ & $2.113 .183 .904,00$ & $799.607 .545,00$ & $3.514 .585 .285,00$ & $2.006 .723 .980,00$ \\
\hline \multicolumn{6}{|c|}{$\begin{array}{l}\text { Todos os valores estão expressos em Reais }(R \$) \text {. } \\
{ }^{1} \text { Valor total da renúncia por ano referente às contribuições. } \\
{ }^{*} \text { Dados encontrados. }\end{array}$} \\
\hline
\end{tabular}

Fonte: (BRASIL, 2015b).

Nos termos do $\S 3^{\circ}$ do art. 212 da Constituição Federal, os recursos a que se refere o caput do mencionado artigo deverão "assegurar prioridade ao atendimento das necessidades 
do ensino obrigatório" (BRASIL, 1988, online). Isso indica que o objetivo principal reside no direcionamento de recursos à Educação Básica e não ao Ensino Superior. Consequentemente, parece equivocado o argumento de que o Estado deixa de alocar verbas nas instituições públicas de Ensino Superior para investi-las nas instituições privadas, mesmo porque o Prouni não funciona mediante a transferência direta de recursos. Do mesmo modo, o Prouni não concorre com a Educação Básica. Isso porque, sendo obrigatórias as parcelas que compõem a Educação Básica, art. 208, inc. I, da CF (BRASIL, 1988), nada afasta a obrigação estatal de universalizar o seu acesso. De certa forma, o Prouni pode ser entendido como resultado de uma escolha estatal em um cenário marcado por duas características conflitantes: (i) a escassez de recursos para permitir a todos o acesso à educação superior; (ii) a escolha constitucional de impor ao Estado obrigações que ultrapassam o mínimo existencial (Educação Básica), para buscar o desenvolvimento nacional (progresso econômico, social e político) e a igualdade material.

Essas circunstâncias exigem que o Estado leve em conta os efeitos de suas ações para que seja possível alocar os recursos públicos escassos de modo a alcançar o melhor resultado, para, assim, atingir a máxima efetivação dos direitos fundamentais, como a educação. É preciso ampliar o acesso ao Ensino Superior a um número maior de indivíduos ao menor custo para o Estado, como faz o Prouni. Contudo, reconhecer o Prouni como política pública eficiente, porque amplia vagas a um menor custo, não significa dizer que o programa não apresente falhas.

No ano de 2009, o Tribunal de Contas da União, em Relatório de Auditoria Operacional sobre o Prouni (BRASIL, 2009b, p. 52-121), apontou inúmeras delas. Dentre outros problemas, destacou que: (i) existiam usuários que possuíam renda superior aos limites estabelecidos pelo programa, tanto no caso de bolsistas parciais quanto bolsistas integrais; (ii) por meio do cruzamento de dados do Registro Nacional de Veículos Automotores (Renavam), identificou-se que mais de 1.700 bolsistas (1.000 integrais e 700 parciais) possuíam veículos em seus nomes, sendo que muitos desses veículos não estavam na categoria de populares, o que aponta para uma incompatibilidade da renda com o programa; (iii) cerca de 1.000 bolsistas encontravam-se cumulando bolsa no Prouni com a realização de graduação em instituição pública e gratuita.

Problemas dessa natureza atentam contra os próprios fundamentos socioeconômicos que levaram à instituição do programa, pois permitem o ingresso de estudantes que não necessitam dos benefícios proporcionados pelo Prouni. No entanto, a existência de certos efeitos negativos é característica comum às políticas públicas de um modo geral. Isso faz que as políticas públicas como o Prouni necessitem de aperfeiçoamento e fiscalização constantes para reduzir ao máximo as externalidades negativas.

A efetiva fiscalização da qualidade de ensino nas instituições credenciadas no programa é essencial para que a política pública não se torne inócua. Se, em um primeiro momento, é necessário garantir o acesso ao Ensino Superior, na sequência, é preciso que o aluno que ingressou pelo Prouni consiga ocupar no mercado de trabalho os melhores 
empregos. Isso pode permitir uma melhor distribuição da riqueza e, consequentemente, uma redução das desigualdades econômicas e sociais, objetivos que parecem ser as finalidades últimas do Prouni.

De qualquer forma, já se pode notar um avanço em relação ao cenário que antecedia à instituição do Prouni, no qual somente 10,4\% dos jovens entre 18 a 24 tinham acesso ao Ensino Superior (BRASIL, 2005a, p. 29). Segundo pesquisa elaborada pelo Sindicato das Mantenedoras de Ensino Superior (Semesp), entidade que representa as universidades particulares do estado de São Paulo, no ano de 2015, a taxa de escolarização líquida, que representa estudantes de 18 a 24 anos matriculados no Ensino Superior, atingiu 16,2\% da população brasileira nessa faixa etária (SINDICATO DAS MANTENEDORAS DO ENSINO SUPERIOR, 2015).

Contudo, os desafios ainda persistem. Nos termos do Censo da Educação Superior do ano de 2012, na parcela 20\% mais rica da população, o percentual de acesso ao Ensino Superior sobe para 36\% dos brasileiros com idade entre 18 a 24 anos. Enquanto isso, na parcela $20 \%$ mais pobre da população, o número cai para 3,5\% dos brasileiros nessa idade (BRASIL, 2014b, p. 29). Esse dado demonstra a desigualdade de acesso à educação superior quando se considera a renda como critério e, portanto, a necessidade de políticas públicas voltadas a permitir o acesso da população mais carente no Ensino Superior até que esse cenário seja modificado.

Além disso, não basta garantir o acesso ao Ensino Superior a um custo menor; a instalação de um novo cenário educacional no país reclama um conjunto de ações, que envolvem desde a universalização do ensino básico de qualidade até o direcionamento de verbas para pesquisa científica e tecnológica nos mais elevados níveis de ensino, dentre outras providências. Contudo, essas medidas surtem efeitos no médio e no longo prazo. Aguardar até que isso ocorra significa perpetuar o ciclo de exclusão. Por isso, essas ações devem ser acompanhadas de outras iniciativas que visem à modificação do atual cenário educacional, como faz o Prouni.

\section{CONCLUSÃO}

A proteção constitucional outorgada ao direito à educação exige que o Estado implemente ações com vistas a ampliar o acesso a esse bem ao maior número possível de cidadãos. Não se trata de uma tarefa fácil, pois a ampliação de vagas em qualquer nível de ensino da rede pública implica a disponibilidade de recursos financeiros por parte do Estado. No caso do Ensino Superior, esse limite orçamentário se impõe com mais intensidade, porque este é um desdobramento do direito à educação que ultrapassa o mínimo existencial (Educação Básica).

O Prouni transforma a renúncia fiscal em vagas para possibilitar o acesso ao Ensino Superior do estudante de baixa renda. Embora essa sistemática extrafiscal represente um custo financeiro temporário para o Estado, que perde em arrecadação, cria-se, em contrapartida, 
um benefício definitivo para aquele beneficiário do programa, que consegue concluir o curso de graduação e, posteriormente, inserir-se em uma melhor posição no mercado de trabalho, o que pode colaborar para a redução das desigualdades sociais e econômicas.

O estudo das repercussões econômicas do Prouni durante a primeira década de existência do programa no período de 2005 a 2015, feito com base na Análise Econômica do Direito pela sua dimensão positiva, aponta que, com relação às atividades de ensino, é menos oneroso ao Estado conceder a isenção de tributos federais em favor das instituições privadas de ensino para que estas concedam bolsas de estudo do que ampliar na mesma proporção as vagas no Ensino Superior público. Isso revela a eficiência da política pública, adotando-se como parâmetro o critério de eficiência de Kaldor-Hicks, já que maximiza a implementação do direito fundamental social à educação com a utilização de menos recursos públicos, o que parece bastante adequado, levando-se em conta a intenção do texto constitucional de garantir mais do que apenas o mínimo existencial, contudo, sem deixar de considerar a limitação orçamentária do Estado.

O Prouni também pode ser entendido como uma política pública de eficiência distributiva, pois reparte melhor os recursos estatais em favor daqueles que mais necessitam, isto é, indivíduos que dificilmente teriam acesso ao Ensino Superior, sobretudo em razão de sua condição econômica. Isso, contudo, não desobriga o Estado de continuar investindo na expansão da rede pública de ensino, já que o sistema escolhido pela Constituição Federal é misto, isto é, conjuga a iniciativa pública com a privada.

Embora o Prouni já tenha colaborado para melhorar o cenário do Ensino Superior no país, a Lei n. 13.005/2014 (BRASIL, 2014a), que aprovou o Plano Nacional de Educação (PNE) para a próxima década, estabeleceu como meta elevar para 33\% a taxa líquida de matrícula no Ensino Superior entre os jovens de 18 a 24 anos (Meta 12). Trata-se de uma pretensão ambiciosa, porém adequada à proteção constitucional dada ao Ensino Superior, enquanto desdobramento do direito fundamental social à educação. Atingir esse objetivo exige a manutenção de uma agenda política voltada à discussão do problema e, mais do que isso, a implementação de políticas públicas capazes de ampliar o acesso à educação superior, bem como aos demais níveis de ensino.

\title{
THE FIRST DECADE OF PROUNI: A STUDY ON EFFICIENCY THROUGH LAW AND ECONOMICS
}

\begin{abstract}
To render the right to education more effective, the State may create public policies, such as the Program "University for All" (Prouni), instituted by the Federal Government in 2005, which grants full and partial scholarships to low-income students in private universities, which, in turn, are exempt from paying federal taxes. In this scenario, the main objective of this article is to assess said public policy in an interdisciplinary perspective within Law
\end{abstract}


and Economics. The article analyzes whether the first decade of Prouni - between the years 2005-2015 - produced effective results for the purpose that gave rise to the concept of such policy, that is, achieving the fundamental social right to education by expanding access to higher education to economically disadvantaged students.

Keywords: Public policies. Education. Program "University for All". Law and Economics.

\section{LA PRIMERA DÉCADA DEL PROUNI: UN ESTUDIO SOBRE LA EFICIENCIA A PARTIR DEL ANÁLIS ECONÓMICO DEL DERECHO}

\section{RESUMEN}

Para tornar más efectivo el derecho a la educación, el Estado puede crear políticas públicas, como el Programa "Universidad para Todos" (Prouni), instituido por el Gobierno Federal en el año de 2005, que concede becas parciales o integrales de estudio a estudiantes de bajos ingresos en instituciones privadas de enseñanza superior, que, en contrapartida, reciben exenciones de tributos federales. En ese escenario, el principal objetivo del presente artículo es evaluar la referida política pública por una perspectiva interdisciplinar, utilizándose del Análisis Económico del Derecho (AED). Así, el artículo analiza si la primera década de existencia del Prouni, entre los años de 2005 a 2015, produjo resultados eficientes para la finalidad que originó la concepción de dicha política pública, o sea, la concretización del derecho fundamental social a la educación por la ampliación de acceso a la Enseñanza Superior a los estudiantes menos favorecidos económicamente.

Palabras-clave: Políticas públicas. Educación. Programa Universidad para Todos. Análisis Económico del Derecho.

1 Segundo o Censo da Educação Superior do ano de 2004, a taxa de escolarização líquida, que expressa as matrículas na educação superior de estudantes na faixa etária de 18 a 24 anos, atingia somente 10,4\% da população brasileira nessa idade naquele ano. Os dados do Censo da Educação Superior de 2004 não levam em conta o Programa Universidade para Todos cujos efeitos só foram registrados a partir de 2005 (BRASIL, 2005a).

2 Segundo dados da Pesquisa Nacional por Amostra de Domicílios do ano de 2003, somente 5\% dos jovens de 18 a 24 anos das famílias com renda per capta de até um salário mínimo e 5\% de não brancos (pretos, pardos e indígenas) chegavam ao Ensino Superior. Os micro dados da Pesquisa Nacional por Amostra de Domicílios de 2003 são disponibilizados pelo IBGE. (INSTITUTO BRASILEIRO DE GEOGRAFIA E ESTATÍSTICA, 2003).

3 Segundo dados do Banco Mundial, em 2014, o Produto Interno Bruto brasileiro atingiu o valor de US $\$ 2.346$ trilhões, o que colocou o país naquele ano na posição de $7^{\mathrm{a}}$ maior economia do mundo (THE WORLD BANK, 2015).

4 Segundo notícia divulgada pelo site da Globo, com base nos dados das declarações de imposto de renda divulgados pela Receita Federal do Brasil, no ano de 2013, apenas 71.440 brasileiros concentravam aproximadamente $22 \%$ das riquezas do país (ALVARENGA, 2015). 
5 As parcelas que compõem a educação básica são identificadas como o núcleo que compõe o mínimo existencial desse direito por vários autores, dentre eles: Fonte (2014, p. 219-220); Bittencourt Neto (2010, p. 121-122); Hachem (2013, p. 359); Barcellos (2011, p. 247).

6 No julgamento do Agravo em Recurso Extraordinário 639.337/SP, o Supremo Tribunal Federal manteve a sentença que havia condenado o Município de São Paulo a matricular crianças em unidades de ensino infantil próximas de sua residência ou do endereço de trabalho de seus responsáveis legais. No caso, o Ministro Relator Celso de Mello destacou que não se ignora que a realização dos direitos depende das possibilidades orçamentárias do Estado, de modo que se comprovada, objetivamente, a incapacidade econômico-financeira do Estado, deste não se poderá razoavelmente exigir, considerada a limitação material, a imediata efetivação do comando fundado no texto constitucional. Entretanto, destacou que não é lícito ao Poder Público criar obstáculo artificial, a partir de indevida manipulação de sua atividade financeira ou político-administrativa, com propósito de inviabilizar o estabelecimento e a preservação de condições materiais mínimas de existência dos cidadãos, raciocínio que se aplica à educação básica (BRASIL, 2011).

7 Os dados dizem respeito aos cursos superiores em Tecnologia, demais cursos de Graduação (Presencial e a distância) (exceto cursos sequenciais) e cursos de pós-graduação Stricto Sensu - Mestrado, Mestrado Profissional e Doutorado (excetuando-se as especializações Lato Sensu) (BRASIL, 2015a).

8 Segundo Matheus Carneiro Assunção, são manifestações extrafiscais: imunidades tributárias; instituição de isenções; reduções de alíquotas (inclusive a zero); reduções da base de cálculo; concessões de créditos presumidos; postergação do prazo de recolhimento de tributos; concessão de anistia ou moratória, dentre outras formas (ASSUNÇÃO, 2011, p. 106).

9 Nesse sentido, apontam os seguintes autores: Almeida (2006, p. 85-113); Machado (2009, p. 22); Saraiva e Nunes (2011, p. 961).

10 Os dados do ano de 2005 foram extraídos do Relatório de Auditoria da Controladoria Geral da União. Os dados referentes aos anos de 2006 a 2015 foram extraídos do site da Receita Federal do Brasil: (BRASIL, 2006a, 2006b, 2007, 2009a, 2010, 2011, 2012, 2013a, 2013b, 2013c, 2014, 2015b).

11 Os dados são do Instituto Nacional de Estudos e Pesquisas Educacionais Anísio Teixeira - INEP, com valores atualizados para 2013 pelo Índice Nacional de Preços ao Consumidor Amplo (IPCA). Os dados dizem respeito aos cursos superiores em Tecnologia, demais cursos de Graduação (Presencial e a distância) (exceto cursos sequenciais) e cursos de pós-graduação Stricto Sensu - Mestrado, Mestrado Profissional e Doutorado (excetuando-se as especializações Lato Sensu). (BRASIL, 2015a).

12 Nesse sentido ver: Brasil (2015c).

13 Segundo dados do Censo da Educação Superior de 2013, existem no país 2391 instituições, sendo 301 instituições públicas e 2090 instituições privadas (BRASIL, 2013d).

14 Os dados referentes aos anos de 2006 a 2015 foram extraídos do site da Receita Federal do Brasil, conforme já referenciado na nota número 10.

\section{REFERÊNCIAS}

ALMEIDA, Sergio Campos de. O avanço da privatização na educação brasileira: o Prouni como uma nova estratégia para a transferência de recursos públicos para o setor privado. 2006. 123 f. Tese (Doutorado) - Universidade Federal Fluminense, Rio de Janeiro, 2006.

ALVARENGA, Darlan. 71 mil brasileiros concentram 22\% de toda riqueza. 2015. Disponível em: <http:/g1.globo.com/economia/noticia/2015/8/71-mil-brasileiros-concentram-22-de-toda-riqueza-veja-dados-da-receita.html>. Acesso em: 29 set. 2015.

ASSUNÇÃO, Matheus Carneiro. Incentivos fiscais em tempos de crise: impactos econômicos e reflexos financeiros. Revista da PGFN, Brasília, v. 1, n. 1, p. 99-121, 2011. 
BARCELLOS, Ana Paula de. A eficácia jurídica dos princípios constitucionais: o princípio da dignidade da pessoa humana. 3. ed. Rio de Janeiro: Renovar, 2011.

BITTENCOURT NETO, Eurico. O direito ao mínimo para uma existência digna. Porto Alegre: Livraria do Advogado, 2010.

BORGES, José Souto Maior. Teoria geral da isenção tributária. 3. ed. São Paulo: Malheiros Editores, 2011.

BRASIL. Constituição Federal. Diário Oficial da União, Brasília, DF, 1988. Disponível em: <http://www.planalto.gov.br/ccivil_03/constituicao/constituicao.htm>. Acesso em: 24 out. 2017.

. Lei n ${ }^{\circ}$ 9.394, de 20 de dezembro de 1996. Diário Oficial da União, Brasília, DF, 1996. Disponível em: < http://www.planalto.gov.br/ccivil_03/leis/L9394.htm>. Acesso em: 24 out. 2017.

. Lei n $n^{\mathrm{O}}$ 11.096, de 13 de janeiro de 2005. Diário Oficial da União, Brasília, DF, 2005b. Disponível em: <http:/www.planalto.gov.br/ccivil_03/ato2004-2006/2005/lei/ 111096.htm>. Acesso em: 24 out. 2017.

. Lei n ${ }^{0}$ 13.005, de 25 de junho de 2014. Diário Oficial da União. Brasília, DF, 2014a. Disponível em: <http://www.planalto.gov.br/ccivil_03/_ato2011-2014/2014/lei/113005. htm >. Acesso em: 20 dez. 2015.

- Ministério da Educação. Instituto Nacional de Estudos e Pesquisas Educacionais Anísio Teixeira. Censo da educação superior 2004: resumo técnico. Brasília: O Instituto Nacional de Estudos e Pesquisas Educacionais Anísio Teixeira, 2005a. Disponível em: < http:// download.inep.gov.br/download/superior/2004/censosuperior/Resumo_tecnico-Censo_2004. pdf > . Acesso em: 2 dez. 2015.

- Ministério da Educação. Instituto Nacional de Estudos e Pesquisas Educacionais Anísio Teixeira. Investimento público direto em educação por estudante em valores reais, por nível de ensino. 2015a. Disponível em: < http://portal.inep.gov.br/web/guest/indicadores-financeiros-educacionais/investimento-publico-direto-em-educacao-por-estudante-em-valores-reais-por-nivel-de-ensino >. Acesso em: 18 dez. 2015.

- Ministério da Educação. Instituto Nacional de Estudos e Pesquisas Educacionais Anísio Teixeira. Censo da educação superior 2012: resumo técnico. Brasília: O Instituto, 2014. Disponível em: <http://download.inep.gov.br/download/superior/censo/2012/resumo_tecnico_censo_educacao_superior_2012.pdf >. Acesso em: 2 dez. 2015

. Ministério da Educação. Instituto Nacional de Estudos e Pesquisas Educacionais Anísio Teixeira. Censo da educação superior 2013. 2013d. Disponível em: < http://download.inep.gov.br/educacao_superior/censo_superior/apresentacao/2014/coletiva_censo_superior_2013.pdf>. Acesso em: 5 nov. 2015. 
. Ministério da Educação. Instituto Nacional de Estudos e Pesquisas Educacionais Anísio Teixeira. Enem por escola. 2015c. Disponível em: <http://download.inep.gov.br// educacao_basica/enem/enem_por_escola/2014/enem_escola_2014.xlsx >. Acesso em: 9 nov. 2015.

. Presidência da República. Controladoria-Geral da União. Relatório de Auditoria: Exercício 2006. 2006b. Disponível em: <http://portal.mec.gov.br/index.php?option=com docman\&view $=$ download\&alias $=20471$-sesu-relatorio-auditoria-2006-pdf\&Itemid $=30192>$. Acesso em: 29 set. 2015.

. Secretaria da Receita Federal. Demonstrativo dos Gastos Governamentais Indiretos de Natureza Tributária 2006. 2006a. Disponível em: <http://www.receita. fazenda.gov.br/publico/EstudoTributario/BensTributarios/2006/DGT2006.pdf $>$. Acesso em: 29 set. 2015.

. Secretaria da Receita Federal. Demonstrativo dos Gastos Governamentais Indiretos de Natureza Tributária 2007. 2007. Disponível em: <http://idg.receita.fazenda.gov.br/ dados/receitadata/gastos-tributarios/previsoes-ploa/arquivos-e-imagens/dgt-2007>. Acesso em: 29 set. 2015.

. Secretaria da Receita Federal. Demonstrativo dos Gastos Tributários: estimativas bases efetivas - 2010. Série 2008 a 2012. 2013a. Disponível em: <http://www.receita.fazenda. gov.br/publico/estudotributario/BensTributarios/2010/DGTEfetivoAC2010Serie2008a2012. pdf > . Acesso em: 29 set. 2015.

. Secretaria da Receita Federal. Demonstrativo dos Gastos Tributários 2009. 2009a. Disponível em: <http://www.receita.fazenda.gov.br/publico/EstudoTributario/BensTributarios/2009/DGT2009.pdf>. Acesso em: 29 set. 2015.

. Secretaria da Receita Federal. Demonstrativo dos Gastos Tributários 2010. 2010. Disponível em: <http://www.receita.fazenda.gov.br/publico/estudotributario/BensTributarios/2010/DGT\%202010.pdf>. Acesso em: 29 set. 2015.

. Secretaria da Receita Federal. Demonstrativo dos Gastos Tributários 2011. 2011. Disponível em: <http://www.receita.fazenda.gov.br/publico/EstudoTributario/BensTributarios/2011/DGT2011.pdf >. Acesso em: 29 set. 2015.

. Secretaria da Receita Federal. Demonstrativo dos Gastos Tributários 2012. 2012. Disponível em: < http://www.receita.fazenda.gov.br/publico/estudotributario/BensTributarios/2012/DGT2012.pdf>. Acesso em: 29 set. 2015.

. Secretaria da Receita Federal. Demonstrativo dos Gastos Tributários 2013. $2013 \mathrm{~b}$. Disponível em: < http://www.receita.fazenda.gov.br/publico/estudotributario/BensTributarios/2013/DGT2013.pdf>. Acesso em: 29 set. 2015. 
. Secretaria da Receita Federal. Demonstrativo dos Gastos Tributários 2014. 2014b. Disponível em: < http://www.receita.fazenda.gov.br/publico/estudotributario/BensTributarios/2014/DGT2014.pdf>. Acesso em: 29 set. 2015.

. Secretaria da Receita Federal. Demonstrativo dos gastos tributários 2015. 2015b. Disponível em: < http://idg.receita.fazenda.gov.br/dados/receitadata/gastos-tributarios/ previsoes-ploa/arquivos-e-imagens/dgt-2015>. Acesso em: 29 set. 2015.

. Secretaria da Receita Federal. Grandes números IRPF anos 2007-2013. 2013c. Disponível em: <http://idg.receita.fazenda.gov.br/dados/receitadata/estudos-e-tributarios-e-aduaneiros/estudos-e-estatisticas/11-08-2014-grandes-numeros-dirpf/gn-irpf-ac-2013. pdf >. Acesso em: 29 set. 2015.

. Supremo Tribunal Federal. ARE 639.337/SP. Relator: Min. Celso de Mello, Segunda Turma São Paulo, 23 de agosto de 2011. Diário da Justiça, 15 set. 2011.

. Tribunal de Contas da União. Relatório de auditoria operacional: Programa Universidade para Todos (ProUni) e Fundo de Financiamento ao Estudante do Ensino Superior (FIES). Brasília: TCU, 2009b. Disponível em: < http://portal.tcu.gov.br/lumis/portal/file/ fileDownload.jsp?inline $=1 \&$ fileId $=8$ A8182A14D92792C014D9283C47B77D7 > . Acesso em: 10 dez. 2015.

CALIENDO, Paulo. Direito tributário e análise econômica do direito: uma visão crítica. São Paulo: Elsevier, 2008.

. Direitos fundamentais, direito tributário e análise econômica do direito: contribuições e limites. Direitos Fundamentais \& Justiça, Porto Alegre, v. 1, n. 7, 2009.

CARVALHO, Cristina Helena Almeida de. Uma análise crítica do financiamento do Prouni: instrumento de estímulo à iniciativa privada e/ou democratização do acesso à educação superior? In: REUNIÃO ANUAL DA ANPED, 34., 2011, Natal. Anais... Natal: ANPED, 2011. CLÈVE, Clèmerson Merlin. Para uma dogmática constitucional emancipatória. Belo Horizonte: Fórum, 2012.

COMPARATO, Fábio Konder. A afirmação histórica dos direitos humanos. 7. ed. São Paulo: Saraiva, 2010.

DAVIES, Nicholas. O governo Lula e a educação: a deserção do Estado continua. Educação \& Sociedade, São Paulo, v. 25, n. 86, p. 244-252, 2004.

FONTE, Felipe de Melo. Políticas públicas e direitos fundamentais. 2. ed. São Paulo: Saraiva, 2014.

GABARDO, Emerson; HACHEM, Daniel Wunder. Responsabilidade civil do Estado, faute du service e o princípio constitucional da eficiência administrativa. In: GUERRA, Alexandre Dartanhan de Mello; PIRES, Luis Manuel Fonseca; BENACCHIO, Marcelo (Coord.). Responsabilidade civil do Estado: desafios contemporâneos. São Paulo: Quartier Latin, 2010. 
GICO JUNIOR, Ivo Teixeira. Metodologia e epistemologia da análise econômica do direito. Economic Analysis of Law Review, Brasília, v. 1, n. 1, p. 7-33, 2010.

GONÇALVES, Oksandro Osdival; RIBEIRO, Marcelo Miranda. Incentivos Fiscais: uma perspectiva da Análise Econômica do Direito. Economic Analysis of Law Review, Brasília, v. 4, n. 1, p. 79-102, 2013.

HACHEM, Daniel Wunder. A maximização dos direitos fundamentais econômicos e sociais pela via administrativa e a promoção do desenvolvimento. Revista Direitos Fundamentais \& Democracia, Paraná, v. 13, n. 13, p. 340-399, 2013.

Tutela administrativa efetiva dos direitos fundamentais sociais: por uma implementação espontânea, integral e igualitária. 2014. 614 f. Tese (Doutorado) - Programa de Pós-Graduação em Direito, Universidade Federal do Paraná, Curitiba, 2014.

INSTITUTO BRASILEIRO DE GEOGRAFIA E ESTATÍSTICA. Pesquisa Nacional por Amostra de Domicílios de 2003. 2003. Disponível em: <ftp://ftp.ibge.gov.br/Indicadores_Sociais/Sintese_de_Indicadores_Sociais_2003/>. Acesso em: 5 dez. 2015.

MACHADO, Antonia Rozimar. O Programa Universidade para Todos-PROUNI e a pseudodemocratização na contra-reforma da Educação Superior no Brasil. 2009. 217 f. Tese (Doutorado) - Universidade Federal do Ceará, Fortaleza, 2009.

NABAIS, José Casalta. O dever fundamental de pagar impostos. Coimbra: Almedina, 1998. NOVAIS, Jorge Reis. Direitos sociais: teoria jurídica dos direitos sociais enquanto direitos fundamentais. Coimbra: Coimbra Editora, 2010.

ORGANIZAÇÃO PARA COOPERAÇÃO E DESENVOLVIMENTO ECONÔMICO. Education at a glance 2013. 2013. Disponível em: < https://www.oecd.org/edu/Brazil EAG2013\%20Country\%20Note\%20(PORT).pdf>. Acesso em: 24 jun. 2016.

PAULSEN, Leandro. Direito tributário: Constituição e Código Tributário à luz da doutrina e da jurisprudência. 9. ed. Porto Alegre: Livraria do Advogado, 2007.

REIS, Sérgio Cabral dos. Educação emancipatória, trabalho decente e desenvolvimento do Brasil no capitalismo parasitário neoliberal: para além do mínimo existencial na jurisdição constitucional democrática. Dat@ venia, Paraíba, v. 7, n. 10, p. 7-28, 2015.

RIBEIRO, Marcia Carla Pereira; CAMPOS, Diego Caetano da Silva. Análise econômica do direito e a concretização dos direitos fundamentais. Revista Direitos Fundamentais \& Democracia, Paraná, v. 11, n. 1, p. 304-329, 2013.

RIBEIRO, Marcia Carla Pereira; GALESKI JUNIOR, Irineu. Teoria geral dos contratos: contratos empresariais e análise econômica. Rio de Janeiro: Campus Jurídico, 2009.

SALAMA, Bruno Meyerhof. O que é pesquisa em direito e economia? Cadernos Direito GV, São Paulo, v. 5, n. 2, p. 5- 58, mar. 2008. 
SARAIVA, Luiz Alex Silva; NUNES, Adriana de Souza. A efetividade de programas sociais de acesso à educação superior: o caso do Prouni. Revista de Administração Pública, Rio de Janeiro, v. 45, n. 4, p. 941-964, 2011.

SARLET, Ingo Wolfgang; FIGUEIREDO, Mariana Filchtiner. Reserva do possível, mínimo existencial e direito à saúde: algumas aproximações. Direitos fundamentais \& Justiça, Rio Grande do Sul, n. 1, out./dez. 2007.

SINDICATO DAS MANTENEDORAS DO ENSINO SUPERIOR. Mapa do ensino superior no Brasil 2015. 2015. Disponível em: <http://convergenciacom.net/pdf/mapa-ensino-superior-brasil-2015.pdf>. Acesso em: 26 jul. 2016.

THE WORLD BANK. Brasil. Disponível em: < http://data.worldbank.org/country/brazil/ portuguese $>$. Acesso em: 20 set. 2015.

Submetido: 19 abr. 2017

Aprovado: 7 jul. 2017 